\title{
"I Have Lived an Autism Experience. Autism is an Interesting Disease": The Life Story of a Young Man with Autism
}

\author{
Yesim Gulec-Aslan ${ }^{1}$, Fidan Ozbey ${ }^{1} \&$ Ugur Yassibas ${ }^{1,2}$ \\ ${ }^{1}$ Department of Special Education, Sakarya University, Sakarya, Turkey \\ ${ }^{2}$ Department of Special Education, Anadolu University, Eskisehir, Turkey \\ Correspondence: Yesim Gulec-Aslan, Education Faculty, Department of Special Education, Sakarya University, \\ Sakarya, Hendek, 54300, Turkey. Tel: 90-264-614-1033. E-mail: yesima@sakarya.edu.tr
}

$\begin{array}{ll}\text { Received: September 20, } 2012 & \text { Accepted: October 15, } 2012 \quad \text { Online Published: November } 27,2012 \\ \text { doi:10.5539/ies.v6n1p74 } & \text { URL: http://dx.doi.org/10.5539/ies.v6n1p74 }\end{array}$

\begin{abstract}
The purpose of the study is to describe the life experiences of a young man who has been diagnosed with Autism Spectrum Disorders (ASD) through a narrative research. In other words, our research aim is to investigate the nature of life and especially the social and school experiences of individual affected by this syndrome.

Data were collected via interviews, meetings, researcher reflections and documents. Inductive approach was used for data analysis. The findings were interpreted and presented into themes. The results were discussed in terms of implications for future research and interventions.
\end{abstract}

Keywords: Autism Spectrum Disorders, narrative research, qualitative methodology

\section{Introduction}

ASD are developmental disorders characterized by important impairments in social and communication behavior. Although ASD are lifelong developmental disorders, education can lead to improvement in skills. While communication and social interaction difficulties are part of the diagnostic criteria for ASD, some of these individuals (especially, individuals with AS and high-functioning autism) have become capable of conveying their own experiences verbally (American Psychiatric Association, 2000; Lovaas, 2003; Müller, Schuler, \& Yates, 2008).

There is a large amount of empirical data about individuals with ASD. However, qualitative research examining real life experiences of mainly the young and adults with ASD are relatively limited. Indeed, reliable information can be gained from the individual himself as primary source through these studies. Thus, experiences of individuals with ASD can be seen from ASD perspective. These research lead to opportunities for these individuals to connect with the specialists who try to encourage them. Additionally, findings of the research have a guiding and supporting role for individuals with ASD and the families (Allen, Hill, \& Heaton, 2009; Carrington, Templeton, \& Papinczak, 2003; Griffith, Totsika, Nash, \& Hasting, 2011). Biographies of these individuals often take place in books or other textual accounts (e.g. Grandin, 2011). Also, it can be seen with limited qualitative studies in literature that there are examinations about experiences of individuals with ASD related to different areas. Carrington and Graham (2001), described the life experiences of boys with AS and their mothers via the qualitative study. The other two studies examined the vocational experiences of the adults with ASD as qualitatively (Hurlbutt \& Chalmers, 2004; Müller, Schuler, Burton, \& Yates, 2003). Some case studies focused on understanding the social experiences of an adolescent with AS (Carrington et al., 2003; Howard, Cohn, \& Orsmond, 2006; Müller et al., 2008). MacLeod and Johnston (2007) conducted a case study with a woman to understand the needs of individuals with AS. Also, Lyman (2008) examined the transition experiences of students with AS via a case study design. Allen et al. (2009) conducted an exploratory study in order to describe the experiences of music for adults with ASD. Punshon, Skirrow, and Murphy (2009) used a phenomenological approach to examine the experiences of adults with AS. Another study examined the support services experiences of adults with AS via phenomenological analysis (Griffith et al., 2011). Finally, the other qualitative study focused on the educational experiences of students with ASD (Humphrey \& Lewis, 2008).

The purpose of this study is to define and understand the life experiences of a young man with ASD referring to his life story. In other words, the main research aim is to investigate the social and school experiences of him and 
to find out his perceptions about life. In accordance with this aim, the sub-questions of the study are listed as: (a) What are the effects of autism on a young man who has ASD?, (b) What are the social life experiences of a young man who has ASD?, (c) What are the school experiences of a young man who has ASD?, (d) What are the future plans of a young man who has ASD?

\section{Method}

This is a qualitative study carried out by a "narrative research" in order to understand the life experiences of a person ASD in a chronological order. This research design focuses on describing the life stories of a single person. The researchers examine the experiences of an individual and discuss the meaning of those experiences. They focus on the person's stories as research data. For this reason, the role of literature has become of secondary importance while the information, based on experience of the person who is focus point, has been foreground. In the narrative research, after the problem is defined, the life story of the person is gained by data collection methods. After this stage, the data are examined and the life story of the person is rewritten. Following the restoring stage, data are coded and themes are created. Finally, the themes are organized to form a meaningful whole and the story of the person is presented as narrative report. (Brantlinger, Jimenez, Klingner, Pugach, \& Richardson, 2005; Creswell, 2005; Savin-Baden \& Van Niekerk, 2007).

\subsection{Participants}

\subsubsection{Kenan}

Kenan was born in 1988. During the research process in 2011, he was enrolled in the fourth year of his engineering program. In January 2012, he graduated from the university and was studying for exams to be employed in state institutions.

Kenan's mother and father are divorced. Kenan who lives with his mother and brother rarely sees his father.

\subsubsection{Diagnostic and Education Process}

Kenan was diagnosed with "ASD/Autism", marked by high functionality, when he was three years and eight months old. The diagnosis was given by a psychiatrist at a university hospital. During the control session held six months after the diagnosis, another psychiatrist working together with the psychiatrist who gave the diagnosis confirmed the diagnosis. That psychiatrist is still following up Kenan. The mother explains her experiences about the diagnosis in the following extract: "His doctor said that if he had not seen Kenan, not known his development story, and just known him recently, he would call the diagnosis as Aspergers disorder, but Kenan was absolutely autistic. The doctor stated that his condition was similar to Aspergers on appearance, but that was high-functioning autism in terms of diagnosis standards."

When we look at the process, we see that although the mother became aware of some differences in her child at an early period, the age when the diagnosis was given is three years and eight months. Some of the statements of the mother regarding the differences in the pre-diagnosis period to which she could not attach a meaning are as follows:

"I always felt restlessness in me since I became pregnant of Kenan. There wasn't any logical explanation of it ... I had a healthy, sweet boy, but I always felt concerned that something would happen to him ... One thing about his infancy which called my attention was his excessive reaction to sounds... Kenan began to act strangely. For example, he used to repel guests visiting us; he used to cry when he saw an unfamiliar person. ... When he reached three years old, he didn't talk but he sang ..."

The mother started to think that her child had autism when she read an accidentally bought psychology book written by a psychiatrist who had made diagnosis. After she read the book, the diagnostic process began: “... I came to a chapter toward the end of the book, with a title which I had never heard in my life: Autism. Should I tell that I started to read or that I began to collapse? I don't know. I read in tears; as though the words I read were exactly describing Kenan. The book said that the child acts as if he/she doesn't see or hear. Indeed, when we called his name, he didn't use to turn to us. The book said that he/she avoids eye contact ... This was describing Kenan again ... He/she watches whirling toys like whirligig or he/she whirls the toys like spinning top. This was how Kenan played..."

Following three months after the diagnosis, the mother fulfilled various educational activities at home with her own efforts since there was no specialist in their town. Some examples related to educational activities organized by the mother are demonstrated below:

“... then it was clear that I needed to get over and do something. I made a plan. I had no trouble in talking with Kenan because I am normally a chatty person. But Kenan didn't like that. I was insisting on talking face to face 
while he was hiding. I was not fed up! He was turning up the volume of the tape for getting rid of me so he was trying to demoralize me. I was silently pulling out the plug and talking again continually ... While we were playing on the bed once, I lay back and lifted him with my legs. Kenan disappeared when I suddenly brought my legs together. I thought that he fell to the ground. He started to laugh. I again lifted him and continued 'Kenan flies, Kenan falls'. We both liked the game. When I lifted him up, he was looking at my face and waiting excitedly for me to put him on the ground. Our first eye contact made a beginning with this game. What could I do more? I reminded that he loved music. I started to sing child songs ... I sang a song again and again. One day I stopped the song in the middle. He tried to open my mouth but I said 'No, you can sing it!' He got angry and shouted. I started to sing again and stopped again. He shouted again. He was trying to pull the song from inside of my mouth with his hand ... He realized that crying was not the solution. At last, I won the fight. I started singing and stopped. I thought that he was not going to sing. However, he was both turning back and running, and singing the rest of the song. Thus, the dialogues started ..."

Following three months after the diagnosis, the doctor noticed positive changes in Kenan who was 3 years and 11 months old then. The doctor suggested getting education from a special education school. They went to the school for 15 days. However, due to the fact that the family lived in another city, a consultancy service was offered for mother to sustain the educational works at home. Unfortunately, the mother gave up training a couple of months later. She explains her reasons as follows: "As I repeated endlessly 'Kenan look at me, Kenan give that to me', he got bored. The mother who was playing and jumping with him had gone; instead there was an unfunny mother who gave directions all the time. We were both bored with this situation. We didn't enjoy any more. I had even difficulty for putting him to the seat in mealtime. I thought he was just four years old. I was going to apply my own rules until he was five...".

Following six months after the diagnosis, psychiatrist suggested Kenan to go to kindergarten when he was 4 years 2 months old. During the same control, with suggestion of other psychiatrist, they started to work with a psychologist from an autism center in a university. They are still visiting the same psychologist for controls. The psychologist began to monitor development once a month and offered consultancy service for mother to provide education at home. In addition, Kenan attended a kindergarten located in their city when he was five. They experienced some troubles in this kindergarten. The mother expressed these as follows: "The teacher distinctly neglected Kenan. He was complaining every time I went there. Kenan was either watching TV all the day or playing with toys on his own." When he started to go to a new kindergarten, Kenan had important development in his speech. He gave answers to some questions such as 'Who is this?'. When he was 7, he went to a primary school. Despite some problems of enrollment process, Kenan started education. “... one of the school authorities told me that he had graduated from psychology department and a child with autism could never go to school so I was supposed not to have a dream about this ... I didn't give up and at last he started to go to the school and had a good teacher. Of course everything wasn't easy; we faced with many problems ..."

After primary school, Kenan continued his secondary and high school.

It is seen that Kenan could not get systematic "special education". The mother provides education herself by using her own knowledge and educational consultancy. Data show that the mother carried out this education in highly creative and suitable ways.

\subsubsection{Mother}

She was born in 1963 and graduated from a high school. After working in private sector, she was retired.

\subsubsection{Researchers}

First researcher has a Ph.D. degree in the Program in Education of the Students with Intellectual Disabilities. Second researcher is a Ph.D. student in Program in Education of the Students with Intellectual Disabilities. They work as lecturer at Sakarya University. Third researcher is a $4^{\text {th }}$ year undergraduate student in Special Education Department.

\subsection{Research Process and Data Collection}

The research process started in April 2011 and finished in December 2011.

The third researcher met Kenan through a friend and mentioned about this experience to the other researchers. Other researchers wanted to meet with Kenan. The third researcher stated that Kenan could share his experiences easily so they met Kenan. After the meeting, all the researchers thought that this experience was needed to be shared examining how the autism was seen from an inner perspective. Also, they wondered about the experiences of Kenan and how he perceived the world. In consequence of the literature review, qualitative research experiences of first two researchers and views of field experts, it was decided to carry out this study 
with "narrative research design". In pursuit of this process, verbal and written permissions were obtained from Kenan and his mother and an agreement was signed as to be behaved in ethical manner. Kenan and his mother were very positive about this event and they remarked that they wanted people to hear their experiences. They showed no objection for sharing their experiences.

Accordingly, the research data were collected through the combination of various methods including interviews, meetings, researcher reflections and documents.

\subsubsection{Interviews}

The semi-structured interview, lasting four hours, was conducted with Kenan.

Interview questions were prepared by researchers with reference to literature review (Carrington et al., 2003; Carrington \& Graham, 2001; Ozonoff \& Rogers, 2003) and the practical experiences of first two researchers. The opinions of the experts were asked for determining the appropriateness of the questions and evaluating from the point of methodology.

The interview was conducted by the third researcher. Even though it is more suggestible that somebody outside of the research team interviews, researchers and experts who study in the area of ASD and qualitative research thought that Kenan could feel more comfortable when he had an interview with the third researcher who is a friend of Kenan.

Besides, the research questions were offered to Kenan two days before to make him feel relaxed and lessen his anxiety, on the basis of literature (Carrington et al., 2003) and the expert opinions.

Before the interview, "interview techniques" education was presented to the third researcher by the second researcher.

\subsubsection{Interview with Mother}

A semi-structured interview, lasting 53 minutes, with Kenan's mother was conducted by the second researcher. The questions were prepared by the first researcher with the approval of a field expert.

Tape recordings of both interviews were gained.

\subsubsection{Meetings}

In the research process, a meeting, lasting four hours, with the mother was held. Experiences of the mother were listened. In the meeting, notes were taken down instead of recording.

\subsubsection{Documents}

The mother gave the researchers her 23 page document in which she wrote her experiences and feelings from pregnancy to then.

\subsubsection{Researcher Reflections}

Researchers' documented informal conversations and self impressions were gathered during research.

\subsection{Data Analysis}

The data were analyzed via inductive approach. First of all, after the participant told a story in the interview, first researcher restored the participant's story. Then, the first researcher examined the data, coded them and composed themes. Finally, themes were organized in a meaningful context and narrative report of the individual story was presented by focusing on the direct references. During this process, researchers checked and validated the transcriptions and restored with the Kenan and his mother.

During data collection and analysis, some strategies were used to establish trusthworthisess: (a) triangulation of multiple sources of evidences, (b) member checking, (c) peer debriefing, (d) detailed description, (e) behaving according to ethical principles (Brantlinger et al., 2005).

\section{Results and Discussions}

The findings are interpreted and presented into five themes: (1) who am I?, (2) autism story, (3) social experiences, (4) school experiences, (5) future plans. The study results about the themes are presented below.

\section{1 "Who am I?"}

The findings related to Kenan's personality, his family and his view for life are pointed out below:

"My name is Kenan. I was born in August 21, 1988. I am studying at the ... Engineering Department ... I am a $4^{\text {th }}$ year student. I usually wake up at 10 to 12 o'clock in the morning. I always eat my breakfast. Then I leave 
home. If I should go to school, I go to school. If my class is at a later hour or if I don't have class that day, I go to internship."

"I have a family of three; mom, elder brother and me ... What makes me happy is to do what has come to my mind immediately. It has been the same since my childhood ... If there is something in my mind, let's say my intention is bad, I mean, it can be setting a trap or beating someone etc. My intention can be good or bad. I mean, if it is in my mind, I do it. If I can't do it, for example, there are many things. For example, I prepare a plan for cheating at home and think all the possible ways beforehand ... I immediately want to do what I thought. It was like this in high school, primary school or in my childhood. Actually there was always only one thing in my mind: to be successful. My obsession with success is so strong that when I fail, I feel that I don't exist. Also, I'm absolutely upset when I am treated unfairly. This unfair treat can be legal or illegal ... I never forgive it in any way. It is valid for everyone, such as my parents, teachers, and friends ..."

Examining the data, it is seen that explanations of Kenan are verified by his mother:

“...he came from school. I wondered when he didn't come out of his room and I went near him. He was melting into tears. I asked what had happened. He was repeating that his teacher had beaten him. It was not possible. That teacher never beats any student. I called his teacher. I learned the real problem. He got three out of five in an exam. I was trying to explain Kenan that every student could get low grades but it was impossible to explain ...", "In high school, when he got lower marks in tests for university exam, it was a matter of life and death and he was making us upset. Also, this ambition for success has helped him to have a good education."

“... I believe that obstinate and ambitious character of Kenan has played an important role in his overcoming the disease. Failure is unacceptable to Kenan. He cannot cope with failure ..."

Besides, the mother expresses Kenan's highly anxious character and cites in the following: "He has anxious personality since he has difficulty in figuring out the situations and rules around him. He is extremely anxious and his drugs are for anxiety. He is aware that people do not understand him."

Also, the mother states that Kenan likes TV series obsessively.

Findings show that Kenan has some characteristics of individuals with ASD and high-functioning autism like dependence on routines, worrying easily and getting stressed, social difficulties and obsessions. Some of these difficulties can be handled with appropriate education, so it can be turned to an encouraging force in their life (Carrington \& Graham, 2001; Munro, 2010; Reichow \& Volkmar, 2010). As it can be seen in the explanations of his mother, the success obsession of Kenan and his ambitious personality, along with education, lead him to be more independent.

\section{2 "Autism Story"}

To understand the standpoints of Kenan about autism and its effect on him, the autism story of Kenan can be seen below:

"I had autism experience, but not at the age of childhood, it appeared and disappeared. It was my fate to enter that road. Yet it was a short road. Autism is an interesting disease. I first became aware of my difference when I was at primary school. I thought that I was very different. Difference has a consistent reason here, you know. For example, the reason of being different in primary school is my ability to think from many aspects... But of course God helps those who suffer from that disease. I mean there are lots of disability types. Some people have no arms, some people have Down syndrome.... Autism has a symmetry symptom. We feel it instinctively and we know why we do that. I can give a better example, from a movie. You may know, because it is your area directly. I saw in 'Rain Man'. You can't gamble with these guys. If you gamble, you may have nothing left to lose, even billion dollars. Just the reason is that the intelligence of the man is perfect. He can do calculation of probabilities but there is a fact. If I did these calculations, I would leave school and live in Vegas. I would earn lots of money. In the movie, the man does everything that is impossible for us. For example, can you memorize the numbers in your phone book? We can't do even if we want ..."

"Autism had some effect on me. It left some troubles. I mean, it is a very troubling disease. It is like mathematical thinking ... There is music as well. My interest for musical instruments is because of this. I don't have any significant skills apart from these .... The trouble it caused to me was this: if you have just noticed, I mostly avoid looking at your face when I talk. But my avoidance is not intentional. I don't know its cause. When I try to make eye contact, it happens that, how can I put it, as if an arc was occurring in-between, as if an electrical jump was happening ... It is not intentional. It is a kind of answer coming from an engineer. Arc is a reference here. You know what I mean. I can explain by drawing, maybe it helps you to understand, okay? ... I don't do this intentionally. To make eye contact is important. In the end, one of the things that will make you 
conspicuous in your relations with the other people is the eye contact. I forced myself a lot, I tried, and you know, I try to keep looking at someone for five or ten minutes, but meanwhile, if I attempt to talk, I utter foolishness. I utter nonsense. I construct something meaningful, logical in my mind, but when I begin to talk; I utter nonsense by looking at the eyes of the person before me. What I say would be irrelevant with the context. I guess there is nothing worse than this issue..." "It is a big trouble that you cannot socialize. I got a number of disadvantages because of what I lived through in the past. When I went to another place for holiday, when my friends in the neighborhood were absent, in particular during high school period, I didn't have friends. You know, I don't come together with any person. It is limited with only family members. Socializing and coming together with friends were more difficult once, but these are not so difficult now. But, of course, you can't talk with every guy. I try to improve myself over the time. I even exert effort to do this. Or I believe I do. Also, I believe that people need to struggle for this issue. When they don't correct their mistakes, the mistakes have priority for them... Success was my biggest obsession. It is such a terrible obsession that without it I can't admit that I am living. Sometimes I ask myself what will happen when I am unsuccessful. In fact, I sometimes want to be unsuccessful .... But I worry about it. Nowadays, I behave in the mood like this; if I'm worried about an event, I tell myself 'come on, let myself be unsuccessful' ..."

Some of the statements of the mother which support what Kenan said about the autism and contain illuminating information about his experiences notably in childhood are as follows:

“... Another memory that I remember from those days is his overreaction to the meal. He used to eat nothing but only tarhana soup, apple and drink milk ...", "I told my mother that Kenan was a very cold child, that he had allergy against man. But now I feel shame for the unjustness I made to him.", “... sleepless nights started for Kenan. He was walking around at nights, and so was I ... he started to color the walls with crayons of his brother. He used to color the wall one night all with blue, and another night all with orange. Next day, I cleaned all the walls. I can't remember how long it lasted. Once, I was very ill and I couldn't clean the walls. That night, he didn't sleep and didn't draw on the walls. Thus, I decided not to clean the walls. When the walls weren't cleaned during a week, he quitted his painting passion.", "He always wanted to wear the same clothes. When you dressed him differently, he threw it immediately. He was growing, so his feet were growing, but again he was insisting on wearing the small size shoes. In the end, I tackled the problem. I bought new shoes, put them a place where he could see. He became familiar with the new pairs a week later so he didn't reject wearing them."

"... I wish you watch him when he walks on the street. He has weird attitudes. He talks to himself. He is not much aware of the people around him. He speaks in a monotone voice ..."

Besides, the mother states that her son comprehends the idioms and uses them in an appropriate context; he can do some jokes; he has consistency in his speech and expresses himself verbally; develops the money concept and buys something by collecting money.

Presented in researcher reflections, some expressions like “ ... he was so introvert in this meeting, he seemed to ignore how he was seen from outside during his communication with people and his talk to himself ...", "He was sitting on the edge of the chair and playing with his hood strings with a sour face. When a mutual friend introduced us, we shook hands without an eye contact ..." advocates the autism story of Kenan.

To summarize, Kenan describes autism as a harsh and interesting disease that has various negative effects on him. He noticed that he has autism syndrome and was different from others in his childhood. Certain features of autism, as Kenan and his mother define, are verified by the literature (for example, social-communication difficulties, partly integration of individuals with ASD and high functioning to the social life, expressing themselves verbally, using different language forms or words, having grammar errors) (Chowdhury, 2009; Ozonoff \& Rogers, 2003). In addition, he points out that he tries to cope with his some characteristics which make his life difficult, but he cannot fix some cases (e.g. eye contact), and also his life becomes worse as he urges to fix these. For this reason, it is very essential that different behaviors and obsessions of individuals with autism may have meaning for them, so instead of stopping these attitudes, these should be turned to acceptable attitudes or some limitations should be used. It is a fact that there should be no change of some attitudes which do not affect the performance for their life (Lovaas, 2003; Scheuermann \& Webber, 2002). To define the provided supports for continuing their life in a functional and independent manner, it is important to regard the features and needs of individual and family. It is crucial to remark how the support makes their life easier (Lovaas, 2003; Reichow \& Volkmar, 2010).

\section{3 "Social Experiences"}

It was seen that Kenan's answers about his social life were highly limited. He could not give clear answers related to the problems particularly in his social life and about coping skills with these troubles. He frequently 
changed the topic and strayed from the focus point. While he was talking about his school friend, his memories were actually about his success and the lessons instead of having social relationships. As he had mentioned before, this limitation can be the reason of "not socializing and having difficulties based on autism". Comparing the literature on autism, it doesn't seem as a surprising indication (Denning, 2007; MacLeod \& Johnson, 2007; Wolfberg, 2003).

The statements of Kenan about his social experiences are presented below:

“... It's a big trouble that you cannot be a social person ... I mean I can't come together with anyone. The people you mostly come together are your family, that's all ... In our childhood, we did lots of things with our two cousins.... We have been very close since our childhood... Now, we see each other only once or twice a year. That was in my childhood..."

"That the friends with whom I am in good terms and whom I love talk about the topic of the conversation only is one of the best qualities for me. I realized many different things in people whom I call friends ... When the topic does not suit them, they stop talking about it. When they talk about what I like, what is interesting for me, it makes me very happy. Let me put it this way: when I went to buy drums, I met with a girl. That evening, from $20.30 \mathrm{pm}$ to $02.00 \mathrm{am}$, we talked about Pokémon only. She loved Pokémon, for sure ..."

"Of course, I have some problems with my friends. In primary school there was nothing like teasing. I was subjected to it, teasing, mostly in secondary school. You can't solve that problem; it is not a solvable issue ..."

The data obtained from the mother support the difficulties in social life of Kenan:

"He did not use to make eye contact ... He used to avoid playing kids ..., "He didn't have many friends in high school, too. He doesn't have many friends now as well ..."

As it is seen in the findings, social handicaps which individuals with ASD experience are present in Kenan. He has great difficulty in coping with them and he thinks he won't overcome it. At that point, it is essential to provide appropriate social skill training. These types of instruction help to lessen the hardships in the social area (Biggs, Simpson, \& Gaus, 2010; Griffith et al., 2011; MacLeod \& Johnson, 2007).

\section{4 "School Experiences"}

School experiences of Kenan by his own words are shown below:

"What I liked much during my school life -primary school, secondary school, high school and including university - is to be 'successful'. Of course, being successful is still an obsession for me. The hardest point in my entire school life was facing with dishonest people ... It compels me... For example, a bald teacher has a problem with a student with hair, like me. It is a big problem for them, but not for me. Just because he is bald, he urges us to cut our hair. He can't stand seeing a man with hair. When you ask the reason why, he answers 'school rules'. He is raving some rules and says that the inspector may come. Actually, that is not his main intention, he doesn't mention about his real intention, being bald... I couldn't cope with these issues since I was so weak. Especially until high school, I was feeling so weak. I wanted my mom to cover my weaknesses. It is even worse than my nature... I'm trying legal ways for uneasy circumstances at university. For example, I was taking a course and its lecturer was so snappish, but also there was an alternative lecturer of the course. I took the course in different way and my petition was approved. After this achievement, I think that when I have certain demonstrations, I can do anything, never mind."

"I was lucky about the teachers; what I mean by saying I was lucky is that if your teachers in the primary school are good, your life goes very well ... If your teachers in the primary school are good, you know, you don't have much trouble about the life, in my opinion. Because, whatever you do, the things and values they have taught to you remain until the end of your life. With some university teachers I have good relationship, but there are some bad guys too and I try to do my best. I don't have any other word about teachers."

"I can talk about my friends. I can't forget that we had a course called 'Probability'. We had a midterm exam and grades were announced. All grades were terrible... Ultimately, it was my turn. Friends asked whether I would check the grades .... I looked and saw the grade but my friends didn't want to see. It was 85. There was a disadvantage of it. They ran after me as I raise average grade. My fault was raising the average, get it ..."

Looking through the mother's states related to school, it is seen that in spite of facing many challenges, they cope with them. As mentioned in previous sections, Kenan had encountered some problems in his first kindergarten but the problems were mostly surpassed in his new kindergarten. Likewise, he completed the primary school with a minimum number of problems thanks to the support of his teacher: "... We were lucky that he had a very good teacher. The teacher always supported us and Kenan. By making Kenan's good qualities 
conspicuous, she gained him a place in the classroom. As she approached the kids with the compassion of a mother, she established respect and order in the classroom. When Kenan entered the class, girls were coming near him, kissing and caressing him as if he was younger. If the teacher had scorned Kenan and let other children tease him, our life would have been more problematic, I guess."

“... He was very successful in primary school. At the end of fifth grade, in year-end show he read poems and sang song... The teacher said 'I will keep my eyes on him, I'm sure he will be very successful' as we were leaving."

Kenan's mother states that after primary school, secondary school and high school period was uneasy for Kenan in terms of interactions with his friends; this period was highly focused on courses and success:

"He started secondary school with an enthusiasm, like every child... The first year of the secondary school was very troubled; his friends were teasing him...He didn't have many friends ... He entered the university exam in the final grade of the high school. My little Kenan has grown up and is entering the university exam. Tears are flowing from my eyes. The image of his starting the school comes before my eyes... Kenan won the university entrance exam. It is not important for me whether he won the university entrance exam or not. What is important for me is that he is able to stand on his own feet. That he finished the high school is enough for me already ..."

As it is seen, Kenan's school experiences and specifically the data related to school friends are very limited as in the Social Experiences section. It is noticed that Kenan's statements for his school experiences, consistent with the data gained from mother, are course and success-focused. Limitation of the school experience information can be connected with social handicaps which individuals with ASD have (Bauminger, Shulman, \& Agam, 2003; Humphrey \& Lewis, 2008). Moreover, it is remarkable that the findings show importance of teachers whose positive attitudes enable favorable development and school life for individuals with ASD. Therefore, it can be said that there is an important role of education environment facilities and qualified inclusive education teachers in the development of these individuals (Chowdhury, 2009; Stahmer \& Ingersoll, 2004).

\section{5 "Future Plans"}

These are the future plans of Kenan:

"When I graduate from the university, I have some plans for the job. If I have enough money, there is a business I want to establish. Private sector is not so attractive for me. I mean, it has many disadvantages. I will take my chance in the public sector. Now, one of the biggest problems of the enterprises is the human relations. They will recruit employees and they will experience some problems concerning such employees ... I mean, there is no relation between my department and providing qualified employees for the enterprises... Of course, I want to do this job because some enterprises had big troubles. The job is not so easy. A new man will come and you will try to realize the man's thoughts. But, what I am doing in my office proves that I can handle it. My experiences in the office give me courage to do it. But, of course, you shouldn't start each job which encourages you ... Falling into disgrace is a high probability. After graduation, I am thinking of working in public sector. Then, after a while, I want to do another thing. I have a dream of finding qualified employees for the enterprises. After retiring I can set up my own business."

"I'm concerned about everything I do. What if something goes wrong? ... I always consider the worst and I want to take precaution. In engineering, you think the possibilities and take measures regarding these. It is the fundamental .... To sum up, you have a target but others joke about this. When you reach your target, no one can joke about you ... All in all, I have fears but I nearly determine my own life style. I can set a goal and achieve it. I can fight against the problems ..."

It is seen that Kenan's future plans are focused on job. He has various objectives in relation to what kind of job he wants. It can be inferred from the statements of Kenan that he has some concerns about social interactions in job environment and attitudes toward him. It is apparent that he thinks that his objectives and confidence will provide him success. Moreover, the office where he interns prepares him for a job. The mother also thinks that the public sector rather than private sector is a better choice when Kenan graduates from the university. She defines that a routine job, like taking stock, is a perfect option for him. She emphasizes that private sector doesn't compel him as mentally, but compels him in terms of social relations, environment, unsteady working hours and rules. The mother states that she has some concerns about Kenan's finding a job and working but she also believes that he will be very successful while working with considerate people. She points out that employers should be trained by the professionals and job opportunities should be provided for individuals like her son. Taking into account the literature, it is evident that individuals with ASD have some difficulties related to job and they need ongoing support (Griffith et al., 2011; Müller et al., 2003). 


\section{Conclusion}

This research is a qualitative study carried out through a "narrative research design" for the purpose of examining the autism from a different aspect. The data, gained from the interviews consisting autism stories of the participant and his mother, were analyzed in accordance with inductive approach.

All findings, consistent with the findings in the literature, support that Kenan has been experiencing difficulties in social-communication skills, which are some of the basic symptoms of autism (Ozonoff \& Rogers, 2003). Besides these difficulties, the study presents that individuals with ASD like Kenan have many strengths which enable them to maintain an independent life. To illustrate, Kenan communicates verbally, interacts and continues his university education. The findings include the elements related to how the participant and his mother perceive the hardships of autism and their experiences in the process of struggling with these hardships. In other words, the study explains the period of finding a place in the life despite some troubles which Kenan still has had. However, examining the literature, it is seen that some of the individuals with ASD can take part in social life to a certain extent and continue their life in an independent way with appropriate education (Humphrey \& Lewis, 2008). In addition, one topic that becomes prominent and draws the attention in this study is the mother becoming aware of the characteristics of her child at an early stage and her efforts after the diagnosis has been done. Kenan did not have a systematic education. The mother, who combined her creativity with counseling service support provided for her, gave education to her son any time he was awake. The fact that the mother never lost her hope, continued struggling and trained her son "without hurting mom-son relation and in an enjoyable way" may have played a positive role in the development of Kenan. It is stressed in literature that the main role of (a) family involvement, (b) educational-psychological service consisting factors that should be noticed by parents in education for their children, in development of both family and the child (Berger, 2008). It is also thought that supportive educational efforts of some teachers in kindergarten and primary school, in other words, successful inclusive practices played an important role in the optimal development of Kenan (Humphrey \& Lewis, 2008; Stahmer \& Ingersoll, 2004).

Autism is listened from a youngster who experienced autism and his mother in this study. It is regarded that the study is important in terms of providing a point of view from an individual who experienced autism and his closest relative. The study provides an opportunity for specialists and others related to autism to reach autism from a primary source. On the other hand, as Kenan mentioned, the study leads him to express himself to the others. The study also presents qualitative data related to young adults with high functioning autism diagnosis since numerous studies in literature focus on early ages. Even though various data collection techniques were used, obtaining information from Kenan through only interview can be seen as limitation. Therefore, in the subsequent research, spending longer time with the participants and using different data collection methods will provide more detailed information. It should be noted that making current and diverse qualitative researches, investigating the real-life experiences of individuals with ASD and their family from their own perspective, will provide significant contributions to the literature. Furthermore, it would be feasible to do similar studies with different participants in order to increase the generalizability of the findings. The researches examining a certain period of life of these individuals (e.g. adolescence period) widen the knowledge about ASD. Moreover, doing researches investigating individuals with ASD who live in different cultures provides view of ASD from different aspects. Lastly, using mixed methods research, the information about these indviduals and education offered to them would be enhanced.

It is thought that specialists and authorized people need to take required steps studying the points of (a) providing psychological counseling and evidence-based education in certain trouble areas. Especially, applying training programs particularly related to problem areas (e.g. social skills training), (b) providing service for minimizing the problems encountered in school, social and work, (c) providing educational and psychological service on some topics for families (e.g. behavior management) (d) organizing trainings to increase qualifications of educators. In conclusion, it is thought that rather than the perspectives of their own side of specialists, families and other people in society, looking from the perspectives from individuals with special need can enable more effective education.

\section{Final words from the mother}

"In what state is Kenan now? Kenan is different but he is studying at a university. He is a handsome boy; he is still avoiding eye contact. He doesn't look at the face of the people when he is talking; he averts his eyes. He is talking not in the manner of a dialogue but in the manner of a soliloquy ... I love Kenan very much. Every manner of my son is beautiful, because I am a mother." 


\section{References}

Allen, R., Hill, E., \& Heaton, P. (2009). 'Hath charms to soothe...': An exploratory study of how high-functioning adults with ASD experience music. Autism, 13(1), 21-41. http://dx.doi.org/10.1177/1362361307098511

American Psychiatric Association. (2000). Diagnostic and statistical manual of mental disorders (4th ed., text rev.). Washington, DC: Author.

Bauminger, N., Shulman, C., \& Agam, G. (2003). Peer interaction and loneliness in high-functioning children with autism. Journal of Autism and Developmental Disorders, 33(5), 489-507.

Berger, H. E. (2008). Parents as partners in education. Families and schools working together. Upper Saddle River, NJ: Pearson Education, Inc.

Biggs, M. J. G., Simpson, C., \& Gaus, M. D. (2010). Using a team approach to address bullying of students with Asperger's syndrome in Activity-based settings children and schools. Children \& Schools, 32(3), 135-142.

Brantlinger, E., Jimenez, R., Klingner, J., Pugach, M., \& Richardson, V. (2005). Qualitative studies in special education. Exceptional Children, 71(2), 195-207.

Carrington, S., \& Graham, L. (2001). Perceptions of school by two teenage boys with Asperger syndrome and their mothers: a qualitative study. Autism, 5(1), 37-48.

Carrington, S., Templeton, E., \& Papinczak, T. (2003). Adolescents with Asperger syndrome and perceptions of friendship. Focus on Autism and Other Developmental Disabilities, 18(4), 211-218.

Chowdhury, U. (2009). Autistic Spectrum Disorders: Assessment and intervention in children and adolescents. British Journal of Medical Practitioners, 2(4), 15-19.

Creswell, W. J. (2005). Educational research. Upper Saddle River, N.J: Pearson.

Denning, B. C. (2007). Social skills interventions for students with Asperger syndrome and high-functioning autism: Research findings and implications for teacher. Beyond Behavior, 16(3), 16-23.

Grandin, T. (2011). The way I see it, revised and ezpanded 2nd edition: A personel loook at autism and Asperger's. Arlinton, TX: Future Horizons.

Griffith, G. M., Totsika, V., Nash, S., \& Hasting, R., P. (2011). 'I just don't fit anywhere': support experiences and future support needs of individuals with Asperger syndrome in middle adulthood. Autism, 1-19 http://dx.doi.org/10.1177/1362361311405223

Howard, B., Cohn, E., \& Orsmond, G., I. (2006). Understanding and negotiating friendships: Perspectives from an adolescent with Asperger syndrome. Autism, 10(6), 619-627. http://dx.doi.org/10.1177/1362361306068508

Humphrey, N., \& Lewis, S. (2008). 'Make me normal': The views and experiences of pupils on the autistic spectrum in mainstream secondary schools. Autism, 12(1), 23-46. http://dx.doi.org/10.1177/1362361307085267

Hurlbutt, K., \& Chalmers, L. (2004). Employment and adults with Asperger syndrome. Focus on Autism and Other Developmental Disabilities, 19(4), 215-222.

Lovaas, O. I. (2003). Teaching individuals with developmentay delays: Basic intervention techniques. Austin, Texas: Pro-Ed.

Lyman, J. A. (2008). "Qualitative Study of Male Asperger's Syndrome Students: Transition from High School to College". Psychology Dissertations. Paper 86. Retrieved from http://digitalcommons.pcom.edu/psychology_dissertations/86

MacLeod, A., \& Johnston, P. (2007). Standing out and fitting in: a report on a support group for individuals with Asperger syndrome using a personel account. British Journal of Special Education, 34(2), 83-88. http://dx.doi.org/10.1111/i1467-8578.2007.00460.x

Müller, E., Schuler, A., \& Yates, G. B. (2008). Social challenges and supports from the perspective of individuals with Asperger syndrome and other autism spectrum disabilities. Autism, 12(2), 173-190. http://dx.doi.org/doi:10.1177/1362361307086664 
Müller, E., Schuler, A., Burton, B. A., \& Yates, G. B. (2003). Meeting the vocational support needs of individuals with Asperger Syndrome and autism spectrum disabilities. Journal of Vocational Rehabilitation, 18, $163-175$.

Munro, J. D. (2010). An integrated model of psychotherapy for teens and adults with Asperger syndrome. Journal of Systemic Therapies, 29(2), 2010, 82-96. http://dx.doi.org/10.1521/jsyt.2010.29.3.82

Ozonoff, S., \& Rogers, J. S. (2003). From Kanner to the millenium: Scientific. advances that have shaped clinical practice. S. Ozonoff, J. S. Rogers., \& R. L. Hendren (Ed.), Autism Spectrum Disorders (s. 3-33). Washington: American Psychiatric Publishing.

Punshon, C., Skirrow, P., \& Murphy, G. (2009). The 'not guilty verdict': Psychological reactions to a diagnosis of Asperger syndrome in adulthood. Autism, 13(3), 265-283. http://dx.doi.org/10.1177/1362361309103795

Reichow, B., \& Volkmar, F. R. (2010). Social skills interventions for individuals with autism: evaluation for evidence-based practices within a best evidence synthesis framework. Journal of Autism and Developmental Disorders, 40(2), 149-66. http://dx.doi.org/10.1007/s10803-009-0842-0

Reilly, C., Campbell, A., \& Keran, P. (2009). Screening for Asperger syndrome in school-age children: issues and instruments. Educational Psychology, 25(1), 37-52. http://dx.doi.org/10.1080/02667360802697589

Savin-Baden, M., \& Van Niekerk, L. (2007). Narrative inquiry: Theory and practice. Journal of Geography in Higher Education, 31(3), 459-472. http://dx.doi.org/0.1080/03098260601071324

Scheuermann, B., \& Webber, J. (2002). Autism: Teaching does make a difference. Belmont: Wadsworth Thomson Learning.

Stahmer, A. C., \& Ingersoll, B. (2004). Inclusive programming for toddlers with autism spectrum disorders: outcomes from the children's toddler school. Journal of Positive Behavior Interventions, 6(2), 67-82.

Wolfberg, P. J. (2003). Peer play and the autism spectrum: The art of guiding children's socialization and imagination: Integrated play groups field manual. Kansas: Autiam Asperger Publishing.

\section{Notes}

Note 1. We thank Kenan and his mother for their participation. We hope that their voice in the journey of autism will reach wider public through various paths. We would like to thank Prof. Dr. Suzanne Carrington who, as a long distance voice, answered our questions about the interview in detail and made important contributions to the conduct of the interview soundly in the course of the research. We would like to thank Prof. Dr. Y1ldiz Uzuner, Prof. Dr. Ali Yıldırım for their opinions; Oktay Taymaz Sarı, Şeyda Demir for trustworthy; Yeliz Ünal, Halil İbrahim Balkul from Sakarya University for post-editing.

Note 2. This manuscript was presented in ABAI 6th Annual Autism Conference, January 27-29, 2012. 